\title{
Processos de Raciocínio Matemático Mobilizados por Estudantes de Cálculo em Tarefas Envolvendo Representações Gráficas
}

\author{
Mathematical Reasoning Processes Mobilized by Calculus Students in \\ Tasks Involving Graphic Representations
}

\author{
André Luis Trevisan * \\ ORCID iD 0000-0001-8732-1912 \\ Eliane Maria de Oliveira Araman ** \\ ORCID iD 0000-0002-1808-2599
}

\begin{abstract}
Resumo
Assumindo a importância do desenvolvimento do raciocínio como competência básica na aprendizagem do Cálculo Diferencial e Integral, objetivamos compreender os processos do raciocínio matemático de estudantes dessa disciplina no trabalho com episódios de resolução de tarefas que envolvem a análise coordenada das mudanças que ocorrem em duas variáveis interdependentes. Adotando uma perspectiva qualitativa de cunho interpretativo, com princípios de uma Investigação Baseada em Design, utilizamos o protocolo escrito e gravações de áudios do trabalho de três grupos de estudantes ao resolverem tarefas envolvendo a criação, interpretação e reflexão a respeito de gráficos. Como resultados, destacamos um processo de construção de conjecturas apoiado em conhecimentos matemáticos que já possuíam, na percepção de relações presentes na tarefa ou, ainda, no senso comum. Além disso, ressaltamos a busca por motivos para validação ou refutação, momento no qual os estudantes resgataram conhecimentos que já possuíam ou construíram novos conhecimentos matemáticos, com a elaboração de novas conjecturas ou aprimoramento de uma já elaborada, novas investigações e tentativas de justificar. Por fim, destacamos o papel desempenhado pela discussão entre os estudantes, bem como o potencial e as limitações das tarefas.
\end{abstract}

Palavras-chave: Ensino de Matemática. Ensino de Cálculo Diferencial e Integral. Raciocínio Matemático. Raciocínio Covariacional.

\begin{abstract}
Acknowledging the importance of reasoning development as a basic competence in learning Differential and Integral Calculus, this work is aimed at understanding the mathematical reasoning processes of students in this discipline, in the process involving the investigation of task resolution that contains the coordinated analysis of changes that happen in two interdependent variables. Adoptin a qualitative perspective of an interpretative nature, with the principles of Design-Based Research, we use the written protocol and audio recordings of the work of three groups of students when solving task involving the creation, interpretation, and reflection about graphics. As a result, we highlight a process construction of conjectures supported by mathematical knowledge that they already had, in the perception of relationships present in the task or, still, in common sense. In addition, we emphasize the search for reasons for validation or refutation, at which time students recovered knowledge they already had or

\footnotetext{
* Doutor em Ensino de Ciências e Educação Matemática pela Universidade Estadual de Londrina (UEL). Professor do Departamento de Matemática da Universidade Tecnológica Federal do Paraná (UTFPR), Londrina, Paraná, Brasil. E-mail: andrelt@utfpr.edu.br.

** Doutora em Ensino de Ciências e Educação Matemática pela Universidade Estadual de Londrina (UEL). Professora do Departamento de Matemática da Universidade Tecnológica Federal do Paraná (UTFPR), Cornélio Procópio, Paraná, Brasil. E-mail: elianearaman @utfpr.edu.br.
} 
built new mathematical knowledge, with the elaboration of new conjectures or improvement of an already elaborated on, new investigations and attempts to justify. Finally, we highlight the role played by the discussion among students, as well the potential and limitations of the tasks.

Keywords: Mathematics teaching. Differential and Integral Calculus Teaching. Mathematical Reasoning. Covariacional Reasoning.

\section{Introdução}

A organização de ambientes de ensino e de aprendizagem de Matemática envolvendo a resolução de tarefas de natureza exploratória (PONTE, 2005, 2014), o trabalho colaborativo (BRODIE, 2010; ELLIS; 2011) e a promoção de discussões (WOOD, 1999; PONTE, 2017; RODRIGUES; MENEZES; PONTE, 2018) são essenciais para que os estudantes ampliem sua capacidade de pensar, e também para que mobilizem processos de raciocínio. Apesar das diferentes perspectivas teóricas assumidas a respeito desse tema (LANNIN; ELLIS; ELLIOT, 2011; PONTE; MATA-PEREIRA; HENRIQUES，2012; JEANNOTTE; KIERAN, 2017; MATA-PEREIRA; PONTE, 2018; MORAIS; SERRAZINA; PONTE, 2018) é consenso entre os autores que o raciocínio matemático - processo dinâmico de conjecturar, generalizar, investigar o porquê e desenvolver e avaliar argumentos - é uma competência básica na aprendizagem matemática. Porém, implementar práticas de ensino com as características supracitadas, em salas de aula regulares, continua a ser um problema em Educação Matemática (LITHNER, 2008).

Em estudos anteriores (COUTO; FONSECA; TREVISAN, 2017; TREVISAN; MENDES, 2017, 2018), discutimos uma proposta de trabalho envolvendo episódios de resolução de tarefas em aulas de Cálculo Diferencial e Integral (CDI), considerando contextos reais de ensino. Apesar dos resultados promissores, pouco ainda sabemos a respeito do desenvolvimento do raciocínio dos estudantes durante esses episódios, em especial no que tange ao raciocínio covariacional (THOMPSON; CARLSON, 2017), bem como a criação, interpretação e reflexão a respeito de fórmulas e gráficos (MOORE; CARLSON, 2012; MOORE; THOMPSON, 2015). Nesse contexto, justifica-se o objetivo de compreender $o$ raciocínio matemático de estudantes de CDI no trabalho com episódios de resolução de tarefas que envolvem a análise coordenada das mudanças em duas variáveis interdependentes.

No intuito de atingir esse objetivo, buscamos reconhecer os processos de raciocínio matemático que estudantes de CDI mobilizam ao resolverem tarefas envolvendo a criação, interpretação e reflexão a respeito de gráficos, bem como evidenciar o papel das tarefas escolhidas e das discussões matemáticas por elas desencadeadas na mobilização desses 
processos. Para tal, organizamos este artigo do seguinte modo: nas seções seguintes, apresentamos o referencial teórico adotado, incluindo estudos acerca dos processos de raciocínio matemático e, mais especificamente, do raciocínio covariacional; na continuidade, apresentamos o contexto em que o estudo foi realizado e os procedimentos metodológicos assumidos. Analisamos e discutimos, então, resoluções apresentadas por grupos de estudantes que cursam CDI em três tarefas, destacando processos de raciocínio que os estudantes mobilizaram e evidenciando o papel das tarefas e das discussões matemáticas envolvidas.

\section{Os processos de raciocínio matemático}

O termo "tarefa", no âmbito da Matemática, usualmente refere-se aos exercícios, problemas, investigações, explorações e projetos em que os estudantes se envolvem (PONTE, 2005) e que lhes fornecem os contextos necessários para o desenvolvimento do raciocínio. Uma tarefa pode ser formulada pelo professor e proposta ao estudante, surgir da iniciativa do próprio estudante, ou resultar da negociação entre ambos, apresentando ou não potencialidades em termos de conceitos e processos matemáticos que pode ajudar a mobilizar (PONTE, 2014).

O engajamento dos estudantes no trabalho com tarefas leva-os a mobilizar diferentes processos do raciocínio matemático, por meio da elaboração de conjecturas e sua posterior justificação, validação ou refutação. No intuito de promover sua aprendizagem, os professores devem propor, aos estudantes, tarefas que os apoiem a compartilhar suas conjecturas, oferecendo oportunidades para revelar e refinar esses processos de raciocínio (LANNIN; ELLIS; ELLIOT, 2011).

De acordo com Jeannotte e Kieran (2017), há uma polissemia quanto ao entendimento da expressão raciocínio matemático, sendo este constituído de múltiplas visões. Pautamos os estudos dessa temática em autores que, de certo modo, apresentam uma compreensão alicerçada em uma essência comum, a produção de novos conhecimentos a partir de outros já existentes. Em síntese, destacam-se as definições sintetizadas no Quadro 1.

\begin{tabular}{|c|c|}
\hline Definição & Referência \\
\hline $\begin{array}{c}\text { Processo de inferência como o que utiliza informação matemática } \\
\text { já conhecida para obter novo conhecimento ou novas conclusões. }\end{array}$ & STYLIANIDES (2009) \\
\hline $\begin{array}{c}\text { Processo conjunto de conjecturar, generalizar, investigar o } \\
\text { porquê, argumentar e refutar se necessário. }\end{array}$ & $\begin{array}{c}\text { LANNIN; ELLIS; ELLIOT } \\
(2011)\end{array}$ \\
\hline $\begin{array}{c}\text { "Processo de comunicação com outros ou consigo mesmo que } \\
\text { matemáticos". }\end{array}$ & $\begin{array}{c}\text { JEANNOTTE; KIERAN } \\
(2017, \text { p. 7) }\end{array}$ \\
\hline $\begin{array}{c}\text { Processo que utiliza "informação já conhecida para obter, } \\
\text { justificadamente, novas conclusões". }\end{array}$ & $\begin{array}{c}\text { MATA-PEREIRA; PONTE } \\
(2018, \text { p. 782) }\end{array}$ \\
\hline Um conjunto de processos mentais complexos através dos quais & MORAIS; SERRAZINA; \\
\hline
\end{tabular}


se obtêm novas proposições (conhecimento novo) a partir de proposições $\quad$ PONTE (2018) conhecidas ou assumidas como verdadeiras (conhecimento prévio).

Quadro 1 - Algumas definições para o raciocínio matemático Fonte: Adaptado de Araman e Serrazina (2020)

Ainda na perspectiva de entendimento do raciocínio matemático, há dois aspectos que podem ser considerados: o estrutural e o de processos (este, nosso foco de interesse). Lannin, Ellis e Elliot (2011) apresentam estes processos: conjecturar, generalizar, investigar o porquê e desenvolver e avaliar argumentos. De modo similiar, Jeannotte e Kieran (2017) apontam que processos de raciocínio podem ser organizados e caracterizados da seguinte forma: (i) a procura de semelhanças e diferenças, como sejam os processos de generalizar, conjecturar, identificar um padrão, comparar e classificar; (ii) a validação, como sejam os processos de justificar e provar; e (iii) o suporte a outros processos de raciocínio, como seja o processo de exemplificar.

Formular conjecturas é um processo no qual o estudante precisa raciocinar sobre as relações matemáticas para desenvolver afirmações sobre elas. Essas afirmações têm o intuito de serem verdadeiras, mas os estudantes ainda não sabem se são. Ao observar as relações e pensar sobre elas, identificam pontos comuns entre vários casos que os ajudam na compreensão do significado de conceitos, símbolos e representações. Conjecturar pode ser entendido como "um processo que envolve raciocínio sobre relações matemáticas, desenvolvendo declarações, nomeadas como conjecturas, que requerem maior exploração para verificar se são verdadeiras ou não verdadeiras” (MORAIS; SERRAZINA; PONTE, 2018, p. 555).

Segundo Jeannotte e Kieran (2017) formular conjecturas é um processo cíclico de: (i) enunciar a conjectura; (ii) verificar se cobre todos os casos e exemplos; (iii) tentar refutar; e (iv) encontrar um motivo que faça com que a conjectura seja verdadeira ou tentar modificá-la. Os estudantes podem criar conjecturas válidas ou inválidas, alicerçadas em raciocínios válidos ou por vezes inválidos, sendo que esses últimos, embora não desejados, podem servir como ponto de partida para o entendimento das ideias matemáticas. Quanto à forma de apresentação de uma conjectura, ela pode ser escrita de várias formas, ou até mesmo existir apenas na mente dos estudantes. Em contexto escolar, eles procuram regularmente padrões e relações e concluem como e porque que eles existem (LANNIN; ELLIS; ELLIOTT, 2011). O processo de identificar padrões, algumas vezes, pode ser confundido com o de conjecturar, porém os dois processos não são iguais (STYLIANIDES, 2009).

Para Lannin, Ellis e Elliot (2011), os estudantes generalizam quando se focam numa ideia ou num aspecto particular de um problema e pensam nele de uma forma mais abrangente. Ainda com relação à generalização, consideram duas etapas importantes: identificar os elementos comuns e alargar o domínio do qual se partiu. Os autores destacam também que as 
generalizações não precisam, necessariamente, envolver estruturas algébricas ou equações. Seguindo este mesmo entendimento, Ponte, Mata-Pereira e Henriques (2012, p. 3) consideram que a generalização "parte de uma conclusão ou conjectura específica para formular uma conjectura de âmbito mais geral". Para além de afirmações sobre objetos particulares, "a Matemática procura fazer afirmações gerais sobre grandes classes de objetos. Por isso, a generalização constitui uma modalidade particularmente importante de formulação de conjeturas" (MATA-PEREIRA, 2018, p. 78).

Comparar é um processo que procura, por meio da percepção de semelhanças e diferenças, construir uma narrativa sobre objetos ou relações matemáticas. Ao comparar exemplos, o estudante pode conseguir enunciar uma conjectura. O processo de comparar pode ocorrer junto com outros processos de raciocínio matemático como generalizar, identificar um padrão ou validar. Já a classificação pode ser entendida como um processo que procura justificar conjecturas de forma objetiva, tendo como base propriedades e definições matemáticas já estabelecidas (JEANNOTTE; KIERAN, 2017).

Com relação aos processos de validação, o processo de justificar requer que os estudantes apresentem motivos pelos quais suas conjecturas podem ser válidas ou não, de forma que possam revisá-las, aprimorando-as ou refutando-as quando necessário (LANNIN; ELLIS; ELLIOT, 2011). Para Jeannotte e Kieran (2017, p. 12), “justificar é um processo social e pode assumir dois formatos: (i) justificar a conjectura que surgiu no processo e (2) relatar a validade que altera o valor epistêmico". O processo de justificar requer que o estudante não apenas mostre que uma afirmação é verdadeira, mas que forneça razões pelas quais ela é verdadeira ou válida em todos os casos possíveis. Dessa forma, o processo de justificar possibilita que os estudantes não apenas desenvolvam "suas habilidades de raciocínio, mas também seu entendimento conceitual" (MORAIS; SERRAZINA; PONTE, 2018, p. 556). Por fim, exemplificar é considerado por Jeannotte e Kieran (2017) como um processo que serve de suporte aos demais, uma vez que auxilia na pesquisa de semelhanças e diferenças como a validação.

No que tange à mobilização desses processos, Rodrigues, Menezes e Ponte (2018, p. 399) apontam o papel dos momentos de discussões matemáticas como capaz de favorecer o “envolvimento [dos estudantes] na apresentação, justificação, argumentação e negociação de significados para os seus raciocínios”. A “capacidade de "dizer o que está efetivamente a pensar e significar o que está efetivamente a dizer' [...] desenvolve-se como resultado de se ter a oportunidade para falar sobre Matemática, para explicar e discutir os resultados obtidos e testar hipóteses" (Relatório Crockcroft, 1982 apud PONTE, 2017, p. 35). Wood (1999) também 
compartilha dessa ideia ao afirmar que é necessário criar um ambiente matemático em que os estudantes possam expressar seus pensamentos, uma vez que o raciocínio matemático melhor se desenvolve em contextos nas quais as interações e discussões são frequentes.

Com o intuito de sintetizar todas essas ideias, partimos de um modelo para os processos de raciocínio matemático proposto por Lannin, Ellis e Elliot (2011), destacando (com base em perspectivas também de outros autores) os entendimentos essenciais em cada um deles, que pode ser visto na Figura 1:

\section{Conjecturar e Generalizar}

- Conjecturar envolve raciocinar sobre relações matemáticas para desenvolver afirmações que ainda não se sabe se são verdadeiras.

- Generalizar envolve identificar regularidades entre casos particulares e estender o raciocínio para classes mais alargadas.

- Generalizar envolve reconhecer o domínio para a aplicação da generalização.

- Conjecturar e generalizar envolve usar e clarificar o significado de termos, símbolos e representações.

\begin{tabular}{|l|l|}
$\begin{array}{l}\text { Investigar o porquê } \\
\text { - Raciocinar } \\
\text { matematicamente } \\
\text { envolve investigar vários } \\
\text { explicar porque a } \\
\text { generalização é } \\
\text { verdadeira ou falsa. }\end{array}$ & $\begin{array}{l}\text { Justificar ou refutar } \\
\text { - Justificar por meio de argumentos lógicos baseados em ideias já } \\
\text { compreendidas anteriormente. } \\
\text { - Justificar uma refutação partindo do fato de uma determinada } \\
\text { afirmação ser falsa. } \\
\text { - Justificar e refutar avaliando a validade dos argumentos utilizado. } \\
\text { - Justificar não é recorrer a argumentos baseados na autoridade, na } \\
\text { percepção, no senso comum ou em exemplos particulares. }\end{array}$ \\
\hline
\end{tabular}

Figura 1 - Um modelo de processos de raciocínio matemático e seus entendimentos essenciais Fonte: Adaptado de Lannin, Ellis e Elliot (2011, p. 11)

\section{O raciocínio covariacional}

Embora criar, interpretar e raciocinar a respeito de fórmulas e gráficos seja uma parte importante da Matemática e, em especial, do CDI, pesquisas apontam dificuldades vivenciadas por estudantes (MOORE; CARLSON, 2012; MOORE; THOMPSON, 2015). Parte disso devese ao fato, em geral, das práticas de ensino focarem na construção de relações estáticas entre duas "coisas", denominadas $x$ e $y$, fazendo com que os estudantes conceituem variáveis como conjuntos de valores específicos, e não as imaginem como "variáveis variando" (FRANK, 2017).

Como consequência, se o estudante visualiza variáveis de uma forma estática, não compreende fórmulas e gráficos como representações da relação entre quantidades variáveis (THOMPSON; CARLSON, 2017), concentrando-se, ou nas manipulações simbólicas, ou em 
“atributos” do gráfico (pontos de intersecção, máximos e mínimos e inclinação da curva). Essa concepção de um gráfico impede que o estudante raciocine a respeito do seu significado em termos da representação da relação entre quantidades relevantes em uma situação, criando uma "desconexão entre as experiências diárias dos estudantes, em que imaginam e experimentam objetos e pessoas se movendo continuamente, e a Matemática escolar, onde são solicitados a pensar em associações pontuais entre valores" (FRANK, 2017, p. 2).

De modo simplificado, o raciocínio covariacional $(\mathrm{RC})$ implica pensar em como os valores de duas quantidades mudam juntos. Este tipo de raciocínio, a partir de valores de duas ou mais quantidades que variam simultaneamente, embora não faça mais parte da concepção contemporânea de função, desempenha um papel crucial na elaboração de conceitos matemáticos e na compreensão de funções contínuas, na conceitualização de taxas e no entendimento de derivadas (taxas de variação instantâneas) e de integrais (variações acumuladas) (THOMPSON; CARLSON, 2017). Assim, "educadores devem oferecer oportunidades para os estudantes conceituarem fórmulas e gráficos como representações de como os valores variáveis de duas quantidades mudam juntos" (FRANK, 2017, p. 3). Em geral, estudantes que se envolvem no RC em um contexto da atividade gráfica devem: (1) construir duas quantidades, (2) imaginar que as medidas dessas quantidades variam suavemente e (3) unir as medidas de duas quantidades construindo um objeto multiplicativo que represente simultaneamente as duas medidas (THOMPSON, 2011).

Frank (2017) elaborou tarefas que buscaram desenvolver essas habilidades do RC, conceituando gráficos como representações emergentes de fenômenos em constante mudança. Para tal, o estudante deve inicialmente conceituar duas quantidades envolvidas em certa situação (reconhecendo um atributo que ele entenda ter uma magnitude mensurável). Em seguida, ele deve imaginar as medidas dessas duas quantidades variando continuamente, concentrando-se na magnitude variável, ao invés dos valores numéricos que a medida da quantidade pode assumir. Após, é necessário coordenar como as duas quantidades variam juntas, imaginando a relação entre suas medidas em um dado momento em seu tempo experimental, construindo um objeto multiplicativo que une a medida dessas duas grandezas. Finalmente, deve coordenar sua concepção da variação suave da medida de cada quantidade, a fim de se envolver na covariação contínua suave. Tais processos são essenciais no trabalho com tarefas que envolvam mudanças que ocorrem em duas variáveis interdependentes, como os que consideramos em nossa pesquisa, e que serão apresentados a seguir. 


\section{Procedimentos metodológicos}

\subsection{Caracterização e contexto da pesquisa}

A investigação que deu origem a este artigo assume uma perspectiva qualitativa de cunho interpretativo (BOGDAN; BIKLEN, 1994), com princípios de uma Investigação Baseada em Design (PONTE et al., 2016), incluindo diversos ciclos envolvendo as fases de preparação, realização e análise retrospectiva de experiências de design de tarefas de natureza exploratória para aulas de CDI (RAMOS; TREVISAN; MENDES, 2019).

Os participantes foram estudantes de um curso superior de Engenharia de uma Universidade Federal do Paraná, que cursaram a disciplina de CDI 1 (sob responsabilidade do primeiro autor) no $2^{\circ}$ semestre de 2017. Essa disciplina, com uma carga de 90 horas-aula, contempla o estudo de funções, limites, derivadas e integrais de funções reais, de uma variável real, e foi organizada em uma estrutura curricular "não usual” (TREVISAN; MENDES, 2017) com conteúdos apresentados ao longo do semestre letivo em formato de espiral.

Iniciou-se o trabalho a partir do estudo de sequências numéricas e do conceito de convergência. Após, um estudo de taxas médias de variação (e, na continuidade, de derivada) foi desenvolvido a partir de diversas sequências de diferença e de quocientes de diferenças e o conceito de integral emergiu do trabalho com sequências de somas parciais, sem que o conceito de limite tenha sido apresentado formalmente até a primeira metade do curso.

Em geral, 25 horas do curso (cerca de 10 encontros de 3 horas-aula de 50 minutos) foram dedicadas ao trabalho com episódios de resolução de tarefa que antecederam o estudo "formal" dos conceitos de limites, derivadas e integrais de funções reais de uma variável real. Para o desenvolvimento das tarefas aqui analisadas (que ocorreram em um desses episódios -3 horasaula de 50 minutos, ao final da primeira metade do curso), os 30 estudantes presentes naquele dia estavam organizados em grupos de três a quatro estudantes. Em um primeiro momento, os grupos trabalharam de forma autônoma, sem intervenção do professor; na continuidade, houve uma discussão coletiva, mediada pelo professor a partir das resoluções dos estudantes, havendo a sistematização de conceitos associados à representação gráfica de funções de uma variável real, como, por exemplo, variáveis dependente e independente, domínio, imagem, escala, (de) crescimento e concavidade.

Assim, as tarefas selecionadas buscaram mobilizar nos estudantes a capacidade de analisar, de maneira coordenada, as mudanças que ocorrem em duas variáveis interdependentes, articulando diferentes representações e utilizando informalmente os conceitos acima listados. 
Além disso, não houve necessidade, em sua resolução, de tomar/adotar valores específicos para as grandezas envolvidas, mas sim imaginar medidas de quantidades variando continuamente (THOMPSON; CARLSON, 2017).

Na tarefa 1 (Figura 2), era necessário: (i) reconhecer grandezas envolvidas na situação (no caso, altura da água na garrafa e tempo); (ii) reconhecer a direção de crescimento (por exemplo, altura e volume aumentam com o tempo, mas o raio aumenta e depois diminui); (iii) identificar o "modo" como a altura de água varia (inicialmente, crescendo a uma taxa decrescente, e depois crescente); (iv) esboçar um gráfico com mudança de concavidade.

Água é derramada em uma garrafa/vaso a uma taxa constante. Use esta informação e a forma do vaso (figura ao lado) para responder às perguntas a seguir. Esboce um gráfico que relacione a altura da água na garrafa com o passar do tempo. Explique o raciocínio que levou ao seu esboço.

Figura 2 - Tarefa da garrafa

Fonte: Adaptado de Carlson et al. (2002)

$\mathrm{Na}$ tarefa 2 (Figura 3) era necessário: (i) identificar o "modo" como as grandezas "tempo" e "números de crimes violentos" relacionam-se; (ii) avaliar se o gráfico apresentado condizia ou não com a descrição.

Um político concorrendo à reeleição declarou que o número de crimes violentos não está mais crescendo e que, atualmente, está sob controle. O gráfico apresentado na figura confirma esta afirmação? Por que sim ou por que não?

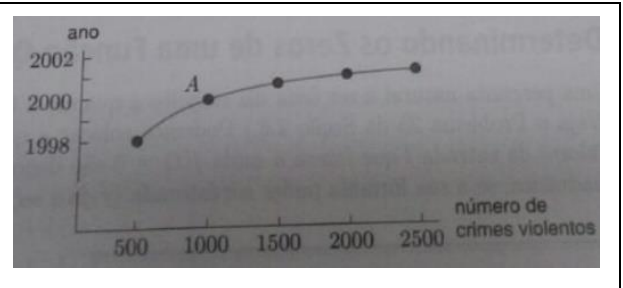

Figura 3 - Tarefa do político

Fonte: Adaptado de Connally et al. (2009)

Por fim, na tarefa 3 (Figura 4), era necessário: (i) reconhecer a direção de crescimento das grandezas envolvidas (perímetro e área crescem); (ii) identificar o "modo" como essas grandezas variam (a taxa de crescimento da área é maior que a do perímetro); (iii) reconhecer que, em ambos os casos, o formato do gráfico é o mesmo (côncavo para cima, se o perímetro for variável independente, e a área como dependente; ou côncavo para baixo, caso contrário).

Construir um gráfico que relacione o perímetro e a área de uma praça supondo que ela tenha formato: (a) Circular; (b) Quadrado.

Figura 4 - Tarefa do perímetro

Fonte: Adaptado de Carlson, Oehrtman e Engelke (2010)

\subsection{Procedimentos para coleta e análise de dados}

Todos os 8 grupos que resolveram a tarefa foram capazes de mobilizar diferentes processos de raciocínio, estabelecendo algum tipo de conjectura e buscando elementos para 
validá-la ou refutá-la. Entretanto, em diversos desses grupos as falas foram monopolizadas por apenas um estudante, com uma discussão bastante sucinta, sem que conjecturas fossem confrontadas pelos demais integrantes do grupo e fossem reformuladas. Assim, na intenção de reconhecer uma maior variedade de processos de raciocínio que foram mobilizados, bem como evidenciar o papel das tarefas escolhidas e das discussões matemáticas nesse contexto, tomouse por critério para escolha dos grupos aqueles na qual houve um maior envolvimento dos estudantes na "apresentação, justificação, argumentação e negociação de significados" (RODRIGUES; MENEZES; PONTE, 2018, p. 399)

Foram utilizados como dados os protocolos escritos dos estudantes e as transcrições de áudios de três grupos de estudantes (Grupo 1 - estudantes A1, A2 e A3; Grupo 2 - estudantes B1, B2 e B3; Grupo 3 - estudantes C1, C2 e C3), sendo escolhidas tarefas nas quais houve uma maior diversidade de falas envolvendo a (re) formulação e validação/refutação de conjecturas. Para análise dos áudios, baseamo-nos nas etapas presentes no modelo de Powell, Francisco e Maher (2004), inicialmente ouvindo-os integralmente; em seguida, identificando momentos significativos e transcrevendo-os, para depois analisá-los. Os resultados estão organizados, sequencial e separadamente, para cada uma das tarefas propostas.

\section{Análise dos resultados}

\subsection{Tarefa 1}

Com o objetivo de esboçar um gráfico que relacionasse a altura de água na garrafa com o passar de tempo, os integrantes do grupo 1 inicialmente elaboraram algumas conjecturas referentes à direção de crescimento e ao modo como as grandezas variariam:
A2: No começo é um pouco "mais maior".
A1: Rápido
A2: "Mais maior" ... depois vai ficando menorzinho.
A1: Sim.
(Diálogo entre estudantes do grupo 1, 2017).

Nesse trecho, conjecturas elaboradas por A2 referem-se à taxa de crescimento da quantidade de água na garrafa, sendo, inicialmente, "um pouco 'mais maior"” e "depois vai ficando menorzinha". Um primeiro esboço do gráfico foi feito por A1 (Figura 5). Na continuidade da discussão, o grupo procurou validar (ou refutar) o esboço proposto:

A1: Então, mas dai o gráfico vai ficar assim, não vai?

A2: É, então, porque ela cresce no começo rápido, depois ela diminui e depois volta mais rápido, por causa daqui [apontando para a parte central da garrafa]. 
A3: Então, mas dai se for medir a altura do vaso pelo diâmetro, é uma reta.

A2: Não, não porque tipo assim, ó! O raio daqui é menor que o daqui [comparando a parte inferior com a parte central da garrafa] então a quantidade de água que for colocar aqui, ela já vai aparecer aqui. Na hora que ele começar a encher a partir desse ponto, ele vai demorar pra estar crescendo e aqui ele vai crescer mais rápido [continua apontando os diâmetros da superficie de água na garrafa conforme ela estaria sendo preenchida com água].

A3: É então, mas estou falando em relação a diâmetro.

A2: Eu acho que ficaria mais ou menos assim [Figura 6]. Seria uma reta?

(Diálogo entre estudantes do grupo 1, 2017).

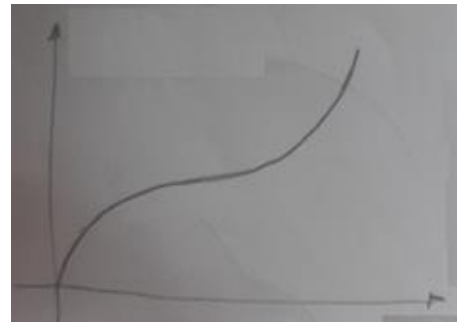

Figura 5 - Primeiro esboço do grupo 1 para a tarefa da garrafa

Fonte: Produção do grupo 1 (2017)

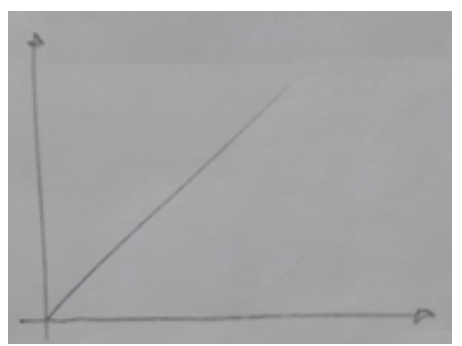

Figura 6 - Segundo esboço do grupo 1 para a tarefa da garrafa Fonte: Produção do grupo 1 (2017)

No intuito de validar o primeiro esboço, A2 elaborou justificativas baseadas no formato da garrafa, imaginando como seriam os diâmetros da superfície de água à medida que ela fosse preenchida. Argumentou que a altura "cresce no começo rápido, depois ela diminui e depois volta mais rápido". A3, por sua vez, apresentou uma nova conjectura: que o gráfico relacionando a altura de água com o diâmetro da superfície de água seria uma reta. A2 novamente elaborou sua justificativa para o formato do gráfico, mencionando agora o raio em sua argumentação. A3 parece ter ficado confuso e não reconheceu que, implicitamente, os argumentos de A2 consideravam o tempo como variável independente, e não o raio da garrafa. Surgiu uma nova representação (uma reta), realizada por A1 com base na conjectura de A3. A discussão seguiu:

A3: Não. Depende, o que vamos relacionar? Volume ou altura

A2: altura de água na garrafa, tá vendo [apontando para o enunciado da tarefa]?

A3: ah sim.

A1: Dai eu acho que seria esse gráfico assim [Figura 5], porque tipo quando começa colocar água aqui ela vai crescer rápido, vai dar uma diminuida na rapidez, olha o tamanho disso aqui [apontando para o centro da garrafa], dai a hora que começar afunilar aqui ele vai crescer mais rápido. Esse gráfico aqui [Figura 5] seria de altura de água. O volume vai ser constante, vai "tá sempre enchendo" na mesma quantidade [Figura 6].

(Diálogo entre estudantes do grupo 1, 2017).

Neste trecho o grupo retornou ao enunciado da tarefa e reconheceu que o gráfico pedido deveria relacionar a altura da água na garrafa com o passar do tempo. A1 reformulou então os argumentos para validar o esboço inicial (Figura 5), baseando-se no "modo" como a altura de água variava. Apontou também o outro gráfico (Figura 6), reconhecendo que, na verdade, ele 
representava o volume de água na garrafa; porém, em sua justificativa utilizou incorretamente a palavra constante, visto que a taxa de variação do volume que era assumida no enunciado da tarefa como sendo constante.

Embora o grupo tenha validado a construção inicial, não fez parte da discussão a elaboração de argumentos que justificassem a mudança de concavidade, ou ainda o fato de o gráfico possuir em sua parte inicial uma concavidade voltada para baixo, e depois para cima. Tais aspectos foram "aceitos" quase que naturalmente por A2 e A3 a partir do esboço elaborado por A1, embora se tratasse de uma justificativa incompleta, que não abordava o conceito de concavidade.

\subsection{Tarefa 2}

Algumas conjecturas acerca do gráfico apresentado foram inicialmente discutidas pelo grupo 2:

B1: [A tarefa pede se]o gráfico apresentado confirma essa afirmação. Se não está mais crescendo. Eu acho que sim, né, porque estava aumentando. Tipo, em dois anos.

B2: É que aqui, ele aumenta assim [apontando para o eixo horizontal. Esse aqui é o ano [apontando para o eixo vertical].

B3: Ele não está parando de crescer?

B1: Eu acho que em dois anos cresceu 500.

B2: Porque ele cresce assim [possivelmente reproduzindo com as mãos o formato do gráfico], não cresce para cima, assim, ai cresceu 500, 2000, 2500.

B1: Está aumentando.

B3: Está mesmo.

(Diálogo entre estudantes do grupo 2, 2017).

Uma conjectura formulada por B2 foi que o número de crimes estava aumentando, pelo fato do gráfico ser côncavo para baixo. Embora fosse uma representação correta, B2 não conseguiu formular, verbalmente, uma justificativa, possivelmente porque lhe faltou um vocabulário mais específico. B3, por sua vez, parecia estar em dúvida e questionou se o gráfico "não está parando de crescer". Possivelmente estivesse se referindo ao fato de a taxa de crescimento ser decrescente, pelo fato do gráfico ser côncavo para baixo. B2 complementou sua justificativa dizendo que, embora o gráfico "não cresce para cima" (referindo-se à concavidade), a quantidade de crimes estaria crescendo (“cresceu 500, 2000, 2500”). Essa justificativa, aparentemente equivocada (por basear-se apenas na variação absoluta de uma das variáveis relacionadas pelo gráfico), foi validada pelos demais integrantes, que disseram: "está aumentando" e "está mesmo". Assim, embora o grupo investigasse e conjecturasse, seus apontamentos basearam-se no senso comum, não contemplando algum argumento matemático 
que permita reconhecê-los como justificativas. Na continuidade da discussão, novas conjecturas e justificativas foram elaboradas:

B2: Normalmente é o inverso, o ano embaixo.

B1: Se estivesse diminuindo, ele iria ser para cima, iria ser tipo assim [risca em uma folha um gráfico com a concavidade voltada para cima].

B3: Verdade.

B1: O número de crimes está embaixo e não em cima, quando normalmente, então se ele [o gráfico] está indo pra cá [sentido horizontal] quer dizer que está aumentando os crimes em pouco tempo. [...]

B3: Tá certo é o que você está falando.

(Diálogo entre estudantes do grupo 2, 2017).

O estudante B2 chamou a atenção para o fato que o tempo estava representado no eixo vertical, e não no horizontal, como costuma ser mais usual. Com base nesse fato, B1 aprimorou a justificativa elaborada anteriormente, argumentando que, pela disposição dos eixos, uma suposta diminuição no número de crimes implicaria em um gráfico côncavo para baixo. $\mathrm{Na}$ verdade, essa concavidade representa uma taxa decrescente do número de crimes em relação ao tempo, e não propriamente uma diminuição da quantidade de crimes. Apesar de incompleta (em construção), essa justificativa foi validada por B3 (“tá certo o que você está falando"). Por fim, a discussão do grupo voltou-se à escolha dos termos para elaborar uma resposta escrita às questões propostas no enunciado da tarefa, ou seja, justificar se o gráfico apresentado confirmava ou não que o número de crimes violentos não estava mais crescendo e que estava sob controle.

B1: Eu escrevi aqui "sim".

B3: Mas é não, porque está crescendo. Ah não, espera aí.

B1: Contrário. Porque foi interpretado corriqueiramente?

B2: Corriqueiro é de todo dia.

B1: Não, é tipo apressado.

B3: Precipitado?

B1: Foi interpretado precipitadamente. Eu escrevi assim [Figura 7]: "o gráfico não confirma a afirmação do político, porque foi interpretado precipitadamente, pois (provavelmente) não leu que o eixo $x$ representa as quantidades de crimes e o y os anos. A interpretação"... escreve a interpretação correta?

B3: Coloca assim: "o gráfico mostra que a taxa de crimes só aumenta"

B1: "Interpretação correta está indicando que os crimes estão aumentando com o passar do tempo".

(Diálogo entre estudantes do grupo 2, 2017). 


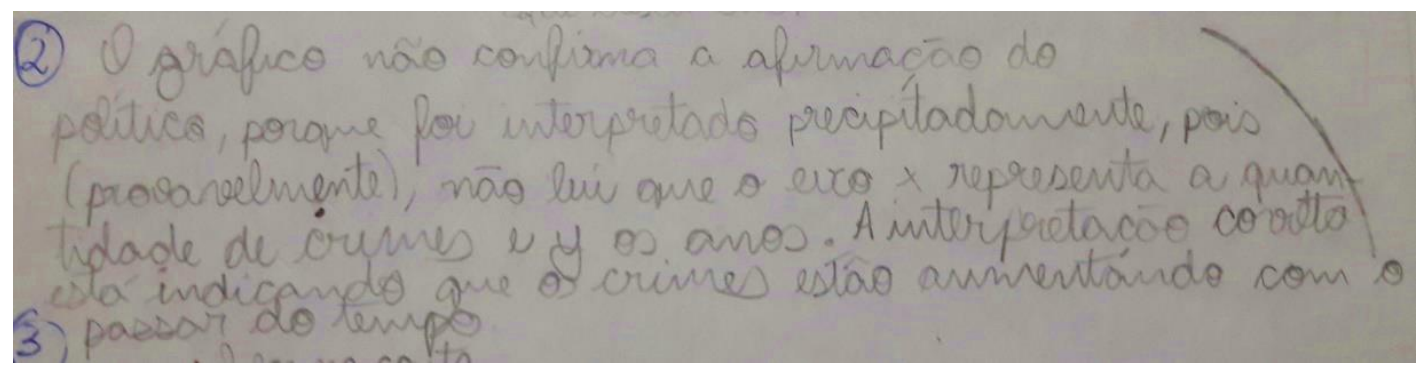

Figura 7 - Resposta elaborada pelo grupo 2

Fonte: Produção do grupo 2 (2017)

Embora, no trecho final do diálogo, B3 tenha sugerido escrever que "a taxa de crimes só aumenta", B1, que estava redigindo a resposta, escreveu apenas que "os crimes estão aumentando com o passar do tempo". Assim, a resposta escrita não agregou os conceitos que o grupo mobilizou na elaboração oral de justificativas, mostrando que, para eles, o termo "taxa" parecia não ter muita importância, ou não ter um significado claro.

\subsection{Tarefa 3}

O grupo 3 iniciou a discussão analisando o caso da praça circular (item $a$ da tarefa):

C1: O perímetro de um circulo é $2 \pi r$.

C2: O comprimento.

C1: E a área é $2 \pi r^{2}$

C2: Não, é $\pi r^{2}$.

C1: A gente não precisa pensar na fórmula. Se aumenta o raio, a área vai aumentar muito mais do que aumenta o perímetro, então, se a gente for construir uma relação entre a área e o perímetro; conforme o perímetro está crescendo, a área está crescendo muito mais. Porque o raio aumenta pros dois. Vamos supor, aumenta 5 pros dois. Esse aqui [área] vai ser 5 ao quadrado, 25, esse aqui [perímetro] vai ser 10, não é dobro, mas esse aqui [área] aumenta mais depressa que esse [perímetro]... Faz sentido?

C2: Faz. E quanto mais o raio vai aumentando mais a área vai aumentando.

C1: Os dois aumentam juntos. E a área aumenta pra cima, aumenta aumentando. Aumenta crescendo.

(Diálogo entre estudantes do grupo 3, 2017).

Os estudantes demonstraram possuir alguns conhecimentos anteriores (comprimento e área de um círculo) e, a partir de tais conhecimentos, $\mathrm{C} 1$ elaborou algumas conjecturas acerca da variação da área e do perímetro. Em sua fala, reconheceu a possibilidade de analisar a relação entre as grandezas envolvidas sem a necessidade de "pensar na fórmula", reconhecendo que a taxa de crescimento da área em relação ao raio era maior que a do perímetro. Nesse caso, utilizou o "raio" implicitamente para analisar como área e perímetro se relacionavam. Suas conjecturas foram validadas e complementadas por $\mathrm{C} 2$, ao afirmar que "faz sentido" o que $\mathrm{C} 1$ disse, e destacar que "quanto mais o raio vai aumentando mais a área vai aumentando". Por fim, a fala de $\mathrm{C} 1$ apresentou, implicitamente, uma conjectura sobre o formato do gráfico ao 
apontar que "a área aumenta para cima". Na verdade, um gráfico na qual a área seja tomada como função do raio (ou do perímetro, como solicitado no enunciado da questão) tem sua concavidade voltada para cima (Figura 8a). Ao tomar o perímetro como função da área, a concavidade volta-se para baixo (Figura $8 b$ ).

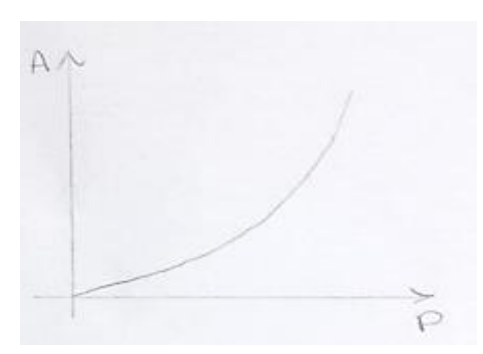

(a)

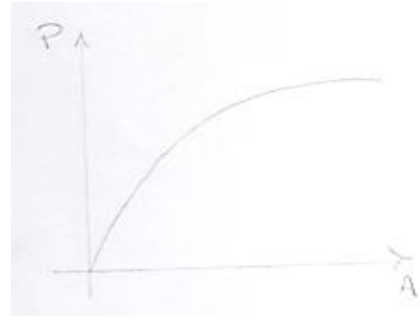

(b)

Figura 8 - Gráficos elaborados pelo grupo 3 para a praça circular Fonte: Produção do grupo 3 (2017)

Continuando a discussão, agora considerando uma praça quadrada, C3 apresentou como conjectura inicial que "o perímetro cresce mais que a área", conforme transcrição a seguir:

C2: E se for um quadrado?

C3: Agora, nesse caso, o perímetro cresce mais que a área.

C2: A área do quadrado é base vezes altura. E o perímetro é a soma de todos os lados.

C3: É, porque ó: a área é lado ao quadrado e o perímetro é quatro vezes o lado.

C2: Não importa o valor. Mesmo que o lado seja 20, temos que $20^{2}$ é 400.

C3: Não sempre. Põe lado igual a 2, por exemplo, a área fica 4. O perímetro fica 8 . É como se no início o perímetro fosse maior do que a área e no final, a área fosse maior que o perímetro. (Diálogo entre estudantes do grupo 3, 2017).

No intuito de avaliar a conjectura apresentada por C3, o estudante C2 recorreu a conhecimentos anteriores referentes ao modo como se calcula a área e o perímetro de um quadrado. Utilizando um valor particular para medida do lado (no caso, 20) como estratégia para tentar validar a conjectura, concluiu que ela seria válida, independentemente do valor escolhida. O estudante $\mathrm{C} 3$, por sua vez, utilizou um contraexemplo (no caso, outra medida de lado) para refutar a conjectura inicial, reformulando-a. Para ilustrar por que a conjectura inicial não era válida, os autores criaram o gráfico mostrado na Figura 9, representando em um mesmo sistema de coordenadas cartesianas tanto o perímetro quanto a área da praça quadrada como funções de medida do lado desse quadrado.

Embora gráficos relacionando diretamente a área e o perímetro, na qual a medida do lado não aparecesse explicitamente, fossem similares àqueles já esboçados pelo grupo anteriormente, para a praça circular (Figura 8), eles não estabeleceram uma comparação entre as duas situações. No intuito de construir uma representação para a praça quadrada, a discussão prosseguiu:

C2: A gente vai encontrar esse maior? Tipo o ponto máximo? A gente vai encontrar esse ponto? 
C3: Ah, tinha que encontrar..

C2: Derivar.

C3: Eu acho que não precisa é só, tipo, um esboço, sabe?

C3: Então a área tipo vai... Não sei, no começo ela vai bem baixinha.

C2: A gente faz tipo, esse crescimento aumentar.

C3: E começa pequeno.

C2: Quando o lado é 3, o perímetro 12, a área é 9. Se o lado é 4, o perímetro é 16, a área é 16.

Dai quando é 4 as duas são iguais... E dai depois a área aumenta.

C1: Se a gente fizer o contrário, tem que ser por área e perímetro?

C2: Sim. Tem.

C1: Pode ser perímetro por área. A gente coloca: o perímetro cresce mais quando passa do quatro... O perímetro cresce quando passa do 4, fica mais bonito.

C1: Esse aqui se a gente quiser fazer perímetro por área, a área cresce mais que o perímetro, então o perímetro cresce menos conforme a área aumenta.

(Diálogo entre estudantes do grupo 3, 2017).

Nesse trecho, C2 inferiu que o gráfico teria um ponto de máximo e sugeriu inicialmente utilizar o conceito de derivada para encontrá-lo (procedimento já explorado anteriormente em sala de aula). Entretanto, optou por utilizar valores particulares de área e de perímetro para determinar para qual medida de lado essas duas grandezas coincidiam. Finalmente, reconheceu a arbitrariedade no posicionamento dos eixos ("pode ser área por perímetro", mas também “pode ser perímetro por área”), obtendo um uma representação gráfica (Figura 10).

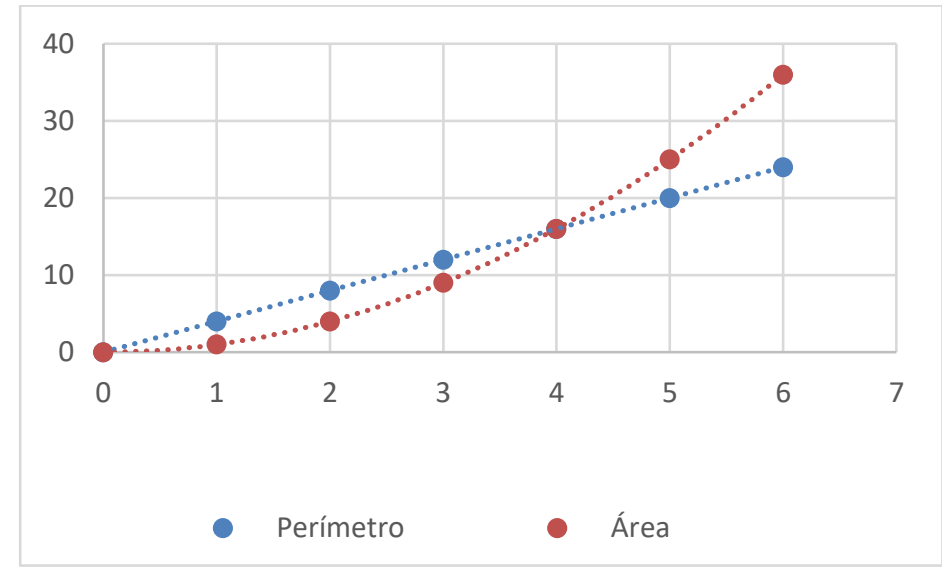

Figura 8 - Gráfico da área e perímetro da praça quadrada como funções do lado Fonte: Produzido pelos autores (2020)

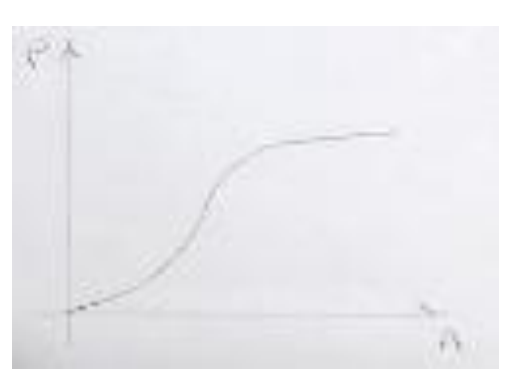

Figura 9 - Gráfico elaborado pelo grupo 3 para a praça quadrada Fonte: Produção do grupo 3 (2017)

Embora incorreto, o gráfico apresentado na Figura 10 ilustra o modo como o grupo buscou subsídios para validar a conjectura que "no início o perímetro fosse maior do que a área e no final, mais para frente, a área fosse maior que o perímetro", e utilizá-los para fundamentar sua construção. Assim, embora a conjectura estivesse correta, ela se referia às situações na qual área e perímetro fossem analisados, em separado, como grandezas dependentes do lado. Nessa perspectiva, o perímetro cresceria a uma taxa maior que área, para valores de lado menores que 4 (como ilustrado na Figura 9). Entretanto, ao consideramos o perímetro como função da área 
(opção feita pelo grupo em seu esboço na Figura 10), a variável dependente cresceria a uma taxa decrescente, o que implicaria em um gráfico côncavo para baixo em todo seu domínio, e não apenas em uma parte dele (como sugerido no esboço apresentado pelo grupo).

\section{Discussão e considerações finais}

O presente artigo tem como objetivo analisar os processos de raciocínio desenvolvidos por estudantes da disciplina de Cálculo Diferencial e Integral ao resolverem tarefas de natureza exploratória, que envolvem a análise coordenada de duas variáveis interdependentes, a partir de discussões entre eles. No que se refere aos processos de raciocínio, os três grupos elaboraram conjecturas, mesmo que ainda de forma incompleta, e fizeram tentativas de validá-las, investigando elementos matemáticos que pudessem justificá-las, num processo dinâmico mediado pela discussão, conforme o proposto por Lannin, Ellis e Elliot (2011).

O grupo 1 elaborou uma primeira conjectura, estando presente, nesse momento, o conhecimento matemático relacionado à taxa e à direção de crescimento (FRANK, 2017; THOMPSON; CARLSON, 2017). Esta conjectura foi ilustrada por meio do esboço de um gráfico, que, na sequência da discussão, os alunos tentaram validar (ou refutar). Segundo Araman, Serrazina e Ponte (2019), o processo de justificação está relacionado com “a identificação de relações que permitem entender porque uma afirmação pode ser verdadeira ou falsa" (p. 468). É o que ocorre na sequência da discussão, em que os estudantes tentam, a partir de novas relações entre os conhecimentos matemáticos (remetem ao formato da garrafa, a sua altura e ao seu diâmetro) validar a conjectura elaboradas por eles.

Entretanto, a discussão proporciona a elaboração de uma nova conjectura ilustrada em um novo esboço de gráfico, que não foi aceita de imediato pelo grupo, dando continuidade a novas discussões e novas relações são estabelecidas. O grupo optou por validar a primeira conjectura e o primeiro gráfico esboçado por meio de uma justificativa. Esta justificativa, embora se apoiasse em "argumentos lógicos baseados em ideias já compreendidas anteriormente" (LANNIN; ELLIS; ELLIOT, 2011, p. 11), apresentou o uso equivocado do termo "constante" e não abordou o conceito de concavidade.

No caso do grupo 2, um de seus membros elaborou uma conjectura, mas não conseguiu exprimir uma justificativa que a validasse, que estava apenas em sua "mente" (JEANNOTTE; KIERAN, 2017) Para Lannin, Ellis e Elliot (2011), o processo de justificar requer que os estudantes apresentem motivos pelos quais suas conjecturas possam ser validadas ou não, o que não ocorreu neste primeiro momento. Entretanto, esta conjectura foi um ponto inicial para a 
discussão do grupo acerca da tarefa buscando dados e garantias na tentativa de sustentar sua conjectura (MATA-PEREIRA; PONTE, 2018), conduzindo-os a complementar sua justificativa que, embora equivocada, foi aceita pelo grupo. Eles ficaram envolvidos em um movimento de investigar o porquê, aceitar e refutar, entretanto, fizeram isso recorrendo no senso comum, percepção, o que não deve ocorrer no processo de justificar (LANNIN; ELLIS; ELLIOT, 2011). Entretanto, apesar de a justificativa final apresentada por eles não se pautar em conceitos matemáticos, eles estão presentes durante a discussão e a investigação do porquê.

O grupo 3 elaborou uma primeira conjectura apoiando-se explicitamente em alguns conhecimentos matemáticos, no caso, comprimento e área de um círculo. A partir disso, perceberam algumas relações que possibilitaram a elaboração de uma nova conjectura, requerendo que novas explorações fossem feitas para validá-la (MORAIS; SERRAZINA; PONTE, 2018) e conduzindo C1 a aprimorar sua primeira conjectura. Por sua vez, C3 elaborou uma nova conjectura, o que faz com que as discussões fossem retomadas e outros conhecimentos matemáticos utilizados (área e perímetro do quadrado), na tentativa de perceber as relações e validá-la ou refutá-la (LANNIN; ELLIS; ELLIOT, 2011).

Nos três grupos analisados, houve um processo de construção de conjecturas apoiado em conhecimentos matemáticos que os estudantes já possuíam, na percepção de relações presentes na tarefa ou, ainda, no senso comum, bem como a busca por motivos para validação ou refutação, momento no qual os estudantes resgataram conhecimentos que já possuíam ou construíram novos conhecimentos matemáticos, com a elaboração de novas conjecturas ou aprimoramento de uma já elaborada, novas investigações e tentativas de justificar, conforme defendido por Lannin, Ellis e Elliot (2011) e adaptado por nós a partir dos dados obtidos, conforme consta na Figura 11.

O papel desempenhado pela discussão entre os estudantes durante a realização da tarefa precisa ser destacado. É de notar que em todos os momentos, seja para elaborar conjecturas, investigar o porquê ou justificar, as ações dos estudantes foram impulsionadas pela discussão entre eles. As aulas nas quais as ideias matemáticas são discutidas com e pelos estudantes são momentos mais oportunos para uma compreensão destas ideias (WOOD, 1999 LANNIN; ELLIS; ELLIOT, 2011). Embora as justificativas apresentadas por eles tenham sido incompletas e carentes de suporte matemático, que poderiam permitir a mudança do valor epistêmico, vale destacar que muitos conhecimentos matemáticos prévios foram utilizados na resolução das tarefas, tais como raio, diâmetro, altura, reta, áreas e perímetros, além de outros que foram aprimorados no processo, em especial tais como direção e taxa de crescimento e concavidade de um gráfico, o que caracteriza o raciocínio matemático conforme a definição de 
Jeannotte e Kieran (2017). Coube ao professor, no momento de discussão coletiva, aprimorar e sistematizar essas justificativas, articulando-as com os conceitos associados à representação gráfica de funções de uma variável real.

\begin{tabular}{|c|c|c|c|}
\hline $\begin{array}{l}\text { Conjecturar } \\
\text { Ora apoiados em conhecimentos } \\
\text { matemáticos, ora apoiados na } \\
\text { percepção e no senso comum. }\end{array}$ & $\begin{array}{l}\text { In } \\
\text { Em } \\
\text { con } \\
\text { mat }\end{array}$ & $\begin{array}{l}\text { o porquê } \\
(\text { novos ou }\end{array}$ & $\begin{array}{c}\text { Justificar } \\
\text { Apoiados em } \\
\text { conhecimentos } \\
\text { matemáticos, quando }\end{array}$ \\
\hline & $\begin{array}{l}\text { Elaboram novas } \\
\text { conjecturas ou } \\
\text { aprimoram a inicial. }\end{array}$ & & $\begin{array}{l}\text { percepção e no senso } \\
\text { comum, mas que eles } \\
\text { consideram suficientes. }\end{array}$ \\
\hline
\end{tabular}

Figura 11 - Processos de raciocínio mobilizados pelos estudantes Fonte: Produzido pelos autores (2020)

O potencial da tarefa também precisa ser considerado. As três tarefas propostas, mesmo tendo como premissa o caráter exploratório, apresentam limitações com relação aos processos de raciocínio. Por exemplo, elas não possibilitam o processo de generalizar. Não queremos dizer com isso que uma tarefa tenha, necessariamente, que possibilitar o desenvolvimento de todos os processos de raciocínio, entretanto, ao fazer a análise do que os estudantes conseguiram fazer, essa questão deve ser considerada.

Um trabalho mais constante com tarefas de natureza exploratória e o raciocínio matemático poderia aprimorar a capacidade dos estudantes de mobilizar mais processos do raciocínio matemático, conduzindo-os a compreender que as justificativas matemáticas são elaboradas a partir de argumentos lógicos baseados em ideias já compreendidas anteriormente, sem recorrer a argumentos baseados em autoridade, percepção, senso comum ou exemplos particulares (LANNIN, ELLIS; ELLIOT, 2011), como ocorreu em alguns casos.

\section{Agradecimentos}

Os autores agradecem à Fundação Araucária e ao CNPq pelo apoio à pesquisa.

\section{Referências}

ARAMAN, E. M. O.; SERRAZINA, M. L. Processos de raciocínio matemático na resolução de tarefas exploratórias no $3^{\circ}$ ano de escolaridade. Revista Paranaense de Educação Matemática, Campo Mourão, v. 9, n. 18, p. 118-136, jan-jun 2020.

ARAMAN, E. M. O.; SERRAZINA, M. L.; PONTE, J. P. "Eu perguntei se o cinco não tem metade": ações de uma professora dos primeiros anos que apoiam o raciocínio matemático. Educação

Matemática Pesquisa, São Paulo, v. 21, n. 2, p. 466-490, 2019. 
BOGDAN, R.; BIKLEN, S. Investigação Qualitativa em Educação: uma introdução à teoria e aos métodos. Porto Alegre: Porto Editora, 1994.

BRODIE, K. Teaching Mathematical Reasoning in Secondary School Classrooms. Nova Iorque: Springer, 2010.

CARLSON, M. P. et al. Applying covariational reasoning while modeling dynamic events: a framework and a study. Journal for Research in Mathematics Education, Reston, v. 33, n. 5, p. 352$378,2002$.

CARLSON, M.; OEHRTMAN, M.; ENGELKE, N. The precalculus concept assessment (PCA) instrument: A tool for assessing reasoning patterns, understandings and knowledge of precalculus level students. Cognition and Instruction, Abingdon, v. 28. n. 2, p. 113-145, 2010.

CONNALLY, E. A. et al. Funções para modelar variações: uma preparação para o cálculo. 3.ed. Rio de Janeiro: LTC, 2009.

COUTO, A. F.; FONSECA, M. O. S.; TREVISAN, A. L. Aulas de Cálculo Diferencial e Integral organizadas a partir de episódios de resolução de tarefas: um convite à insubordinação criativa.

Revista de Ensino de Ciências e Matemática, São Paulo, v. 4, p. 50-61, 2017.

ELLIS, A. B. Generalizing-Promoting Actions: How Classroom Collaborations Can Support Students' Mathematical Generalizations. Journal for Research in Mathematics Education, Reston, v. 42, n. 4, p. 308-345, 2011.

FRANK, K. M. Examining the Development of Students' Covariational Reasoning in the Context of Graphing. 2017. Dissertation (Doctor of Philosophy) - Arizona State University, 2017.

JEANNOTTE, D.; KIERAN, C. A conceptual model of mathematical reasoning for school mathematics. Educational Studies in Mathematics, Utrecht, v. 96, n. 1, p. 1 - 16, 2017.

LANNIN, J.; ELLIS, A. B.; ELLIOT, R. Developing essential understanding of mathematics reasoning for teaching mathematics in prekindergarten-grade 8. Reston: National Council of Teachers of Mathematics, 2011.

LITHNER, J. A research framework for creative and imitative reasoning. Educational Studies in Mathematics, Utrecht, v. 67, n. 3, p. 255-276, 2008.

MATA-PEREIRA, J. Ações do professor para promover o raciocínio matemático. 2018. Tese (Doutorado em Educação) - Instituto de Educação, Universidade de Lisboa, Lisboa, 2018.

MATA-PEREIRA, J.; PONTE, J. P. Promover o Raciocínio Matemático dos Alunos: uma investigação baseada em design. Bolema, Rio Claro, v. 32, n. 62, p. 781 - 801, 2018.

MORAIS, C.; SERRAZINA, L.; PONTE, J. P. Mathematical Reasoning Fostered by (Fostering) Transformations of Rational Number Representations. Acta Scientiae, Canoas v. 20, n. 4, p. $552-$ $570,2018$.

MOORE, K. C.; CARLSON, M. P. Students' images of problem contexts when solving applied problems. Journal of Mathematical Behavior, New Jersey, n. 31, p. 48-59, 2012.

MOORE, K. C.; THOMPSON, P. W. Shape thinking and students' graphing activity. In: FUKAWACONNELLY, T. et al. (ed.). Proceedings of the 18th Meeting of the MAA Special Interest Group on Research in Undergraduate Mathematics Education. Pittsburgh: RUME, 2015, p. 782-789. 
PONTE, J. P. Gestão curricular em Matemática. In: GTI (Ed.). O professor e o desenvolvimento curricular. Lisboa: APM, 2005, p. 11-34.

PONTE, J. P. Tarefas no ensino e na aprendizagem da Matemática. In: PONTE, J. P. (org.). Práticas Profissionais dos Professores de Matemática. Lisboa: Instituto de Educação da Universidade de Lisboa, 2014. p.13-27.

PONTE, J. P. Discussões coletivas no ensino aprendizagem em Matemática. In: GTI (Ed.). A prática dos professores: planificação e discussão coletiva na sala de aula. Lisboa: APM, 2017. p. 33-56.

PONTE, J. P.; CARVALHO, R.; MATA-PEREIRA, J.; QUARESMA, M. Investigação baseada em design para compreender e melhorar as práticas educativas. Quadrante, Lisboa, v. 25, n. 2, p. 77-98, 2016.

PONTE, J. P.; MATA-PEREIRA, J.; HENRIQUES, A. O raciocínio matemático nos alunos do Ensino Básico e do Ensino Superior. Práxis Educativa, Ponta Grossa v. 7, n. 2, p. 355-377, 2012.

POWELL, A. B.; FRANCISCO, J. M.; MAHER, C. A. Uma abordagem à análise de dados de vídeo para investigar o desenvolvimento de ideias e raciocínios matemáticos de estudantes. Bolema, Rio Claro, v. 17, n. 21, p. 81-140, 2004.

RAMOS, N. S.; TREVISAN, A. L.; MENDES, M. T. Delineamento de tarefas de cálculo diferencial e integral envolvendo sequências numéricas: análise de um processo. Alexandria, Florianópolis, v. 12, p. 27-49, 2019.

RODRIGUES, C.; MENEZES, L.; PONTE, J. P. Práticas de Discussão em Sala de Aula de Matemática: os casos de dois professores. Bolema, Rio Claro, v. 12, n. 61, p. 398-418, 2018.

STYLIANIDES, G. Reasoning-and-proving in school mathematics textbooks. Mathematical Thinking and Learning, Abingdon, v. 11, n. 4, p. 258-288, 2009.

THOMPSON, P. W. Quantitative reasoning and mathematical modeling. In: HATFIELD, L.L.; CHAMBERLAIN, S.; BELBASE, S. (Ed.). New perspectives and directions for collaborative research in mathematics education. Laramie: University of Wyoming Press, 2011. p. 33-57. v. 1.

THOMPSON, P. W.; CARLSON, M. P. Variation, covariation, and functions: Foundational ways of thinking mathematically. In: CAI, J. (Ed.). Compendium for research in mathematics education. Reston: National Council of Teachers of Mathematics, 2017. p. 421-456.

TREVISAN, A. L.; MENDES, M. T. Integral antes de derivada? Derivada antes de integral? Limite, no final? Uma proposta para organizar um curso de Cálculo Integral. Educação Matemática Pesquisa, São Paulo, v. 19, n. 3, p. 353-373, 2017.

TREVISAN; A. L.; MENDES, M. T. Ambientes de ensino e aprendizagem de Cálculo Diferencial e Integral organizados a partir de episódios de resolução de tarefas: uma proposta. Revista Brasileira de Ensino e Tecnologia, Ponta Grossa, v. 11, n. 1, p. 209-227, 2018.

WOOD, T. Creating a context for argument in mathematics class. Journal for Research in Mathematics Education, Reston v. 30, n. 2, p. 171-191, 1999. 